\title{
Cutaneous invasion from sarcomatoid urothelial carcinoma: clinical and dermatopathologic features ${ }^{*}$
}

Fred Bernardes Filho ${ }^{1}$

Alessandro Severo Alves de Melo ${ }^{2}$

Andréa Rodriguez Cordovil Pires ${ }^{2}$

Omar Lupi $5^{5,6,7}$

\author{
Daniel Gama das Neves² \\ Margareth Fernandes da $\mathrm{Cruz}^{3}$ \\ Bernard Kawa Kac ${ }^{4}$
}

\begin{abstract}
In Brazil, without considering the non-melanoma skin tumors, bladder cancer in men is the eighth most common, and the urothelial carcinoma or transitional cell carcinoma is the most common among these. Cutaneous metastases from urothelial neoplasms appear as single or multiple erythematous, infiltrated nodules or plaques, and like other cases of distant disease, it is indicative of poor prognosis. The invasive urothelial carcinoma is recognized for its ability to present divergent differentiation and morphological variants. The sarcomatoid urothelial carcinoma is a rare cancer that consists of two different components: one composed of epithelial tissue and the other with sarcomatoid features of mesenchymal origin. The authors describe a case of cutaneous metastasis of sarcomatoid urothelial carcinoma in a 63-year-old male patient.
\end{abstract}

Keywords: Immunohistochemistry; Urinary bladder Neoplasms; Sarcoma

\section{INTRODUCTION}

Vesical neoplasms are important in view of the severity of symptoms involved, high recidivism rates and treatment morbidity. ${ }^{1}$ Bladder tumor is the most common genitourinary tract cancer, the ninth most common cancer in the world, with over 330,000 new cases/year, more than 30,000 deaths/year and a 3.8:1 rate between men and women. ${ }^{2,3}$ In Brazil, without taking into account non melanoma skin cancer, bladder cancer is the eighth most frequent in male patients (6.89/100 thousand men); in women, it is the 15th most frequent (2.15/100 thousand women). ${ }^{4}$

The smoking habit is the most important risk factor for this type of cancer, responsible for approx- imately $50-65 \%$ of new cases in men and $20-30 \%$ of cases in women. ${ }^{5}$ The second risk factor to be emphasized is occupational exposure (polycyclic aromatic hydrocarbons, formaldehydes and solvents) ${ }^{6}$ Chronic aggression to vesical mucosa resulting from long periods of time wearing a vesical catheter, untreated vesical lithiasis and cystitis caused by Schistosoma hematobium are also associated with the onset of squamous cell carcinoma in the bladder. ${ }^{1}$

The most common bladder cancer is the urothelial cell carcinoma, also known as transitional cell carcinoma. In approximately $30 \%$ of patients it is only diagnosed when there is invasion of the muscle layer. ${ }^{6}$

Received on 01.10.2014

Approved by the Advisory Board and accepted for publication on 04.12.2014

Study carried out at the laboratory Fonte Medicina Diagnóstica - Niteroi (RJ), Brazil.

Financial Support: None.

Conflict of Interests: None.

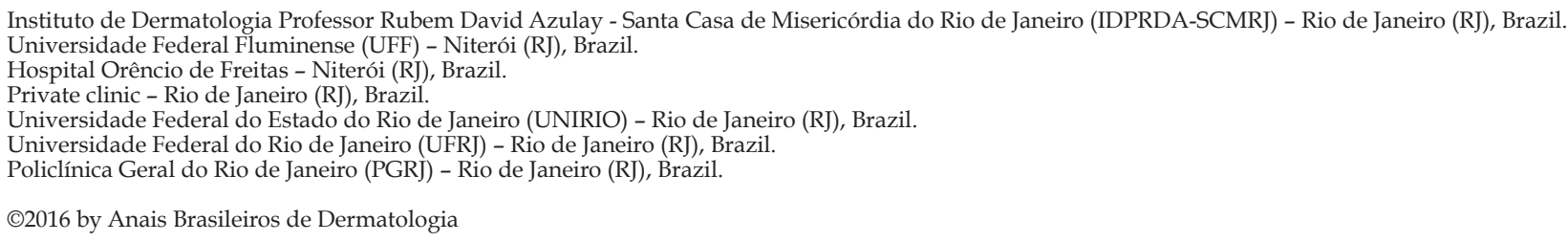




\section{PATHOLOGICAL ANATOMY}

Histologically considered, the wall of the urinary bladder is composed of three layers: one external tunica adventitia of connective tissue which, in some areas, is lined by a serous peritoneal membrane, a non striated tunica muscularis (detrusor bladder muscle) and an internal mucosa membrane that lines the interior of the bladder (tunica mucosae or urothelium). ${ }^{7}$

Normal urothelium is formed by three to seven cellular layers that are on top of the corion, which contains the muscular layer of the mucosa. ${ }^{8}$ The deeper cells are called basal and the superficial ones have a wide and flat umbrella shape. Among them there are one or more layers of intermediary cells. ${ }^{1,7,8}$

The transitional or urothelial cell carcinoma is different from normal epithelium as it presents an increased number of cellular layers, with a papillary aspect and loss of cellular architecture and polarity. They may present a papillary, nodular, sessile, infiltrative and mixed pattern. They may grow in depth, invading the corion and the muscular layer characteristic of the bladder. ${ }^{1,9}$

\section{CUTANEOUS METASTASIS}

The cutaneous metastasis of a visceral primary tumor is uncommon and its incidence varies between $0.2 \%$ and $10.4 \%$; the most common primary tumors that metastasize the skin depend on the gender of the affected patient and include breast $(69 \%)$, followed by colon $(9 \%)$, lung $(4 \%)$ and ovary $(4 \%)$ in women and lung $(24 \%)$, followed by colon $(19 \%)$ and head and neck tumors (12\%) in men. ${ }^{10-12}$ As regards malignancy of the genitourinary tract, the incidence of skin involvement is between $1.1 \%$ and $2.5 \%$ of cases, corresponding to $3.4 \%$ of renal cell carcinomas and only $0.84 \%$ of urothelial carcinomas. The transitional cell carcinoma usually metastasizes to lymph nodes, liver, lungs, bones and adrenal glands; cutaneous metastasis is considered rare. . $^{13,14}$

Visceral tumors may metastasize to the skin through four mechanisms: (a) direct invasion from a neoplasm of underlying tissue (contiguity); (b) iatrogenic implantation on the surgical wound; (c) lymphatic dissemination; (d) hematogenic dissemination. ${ }^{10,12,13}$

It should be noted that even superficial urothelial carcinomas show some kind of dissemination in $20 \%$ of the cases; there may be cutaneous metastasization even in absence of muscle-invasive disease. ${ }^{13,15}$

Clinically, cutaneous metastases of urothelial neoplasms appear as plaques or either single or multiple nodules, erythematous, infiltrated, with an ulcerated or necrotic aspect. Diagnosis may become difficult as other primary dermatoses, such as hemangiomas, keratoacanthomas, herpes zoster, erysipelas, boils or even dermatitis associated with chemotherapy are mimetized. They tipically affect the dermis rather than the epidermis. ${ }^{13-15}$

Histologically, cutaneous metastases of a visceral carcinoma demonstrate an uncontrolled infiltrative growth with atypical epithelial cells disposed as single cells, narrow cords and nests, moving through collagen bundles in the dermis (Figure 1). ${ }^{16}$ Lymphatic vascular invasion may be present, which favors the metastatic origin of the tumor. Cutaneous metastases may cytologically resemble the primary tumor. However, they may be little differentiated and require immunohistochemical staining to determine their primary origin. ${ }^{13,16,17}$

\section{CASE REPORT}

Male patient, 63 years old, mentioned history of hematuria and intermitent abdominal pain for seven months. He had undergone multiple treatments for urinary infection without resolution of clinical symptoms. A genitourinary tract ultrasound scan revealed a nodular and hyperechogenic image, measuring 37 $\mathrm{mm}$ in its larger diameter, located in the left anterolateral wall of the bladder. As there was suspicion of vesical tumor, he underwent transurethral bladder resection; complementary laparotomy and cystectomy were required due to perforation of the organ.

Histopathological examination of the lesion revealed high grade urothelial carcinoma (WHO/ISUP) with invasion of the muscle layer and presence of embolus in lymph vessel. Pathological staging: pT2a, $\mathrm{pNx}, \mathrm{pMx}$.

One month after surgery the patient was hospitalized due to abdominal distension and pain. During the physical examination he was without fever, eupneic, pulse $88 \mathrm{bpm}$, blood pressure $110 \times 70 \mathrm{mmHg}$. At the dermatological examination were observed: an infraumbilical scar, an erythematous-purpuric plaque, infiltrated, measuring about $10 \times 5 \mathrm{~cm}$ at the hypogastrium, fistula with urine drainage at midline, infraumbilical region and two erythematous-wine colored nodules at midline, suprapubic region (Figure 2).

Tomography of the abdomen and pelvis with intravenous contrast demonstrated free liquid; multiple peritoneal nodules of irregular outline and heterogeneous enhancement, suggesting secondary implants; important thickening of right vesical wall associated with densification of adjacent fat and mass of heterogeneous enhancement infiltrating the abdominal wall up to the epidermis in the hypogastrium region and on the pathway of the surgical incision, where densification of subcutaneous fat planes and cutaneous nodules can be observed (Figure 3 ).

A biopsy of one of the nodules located in the midline scar was made and the histopathological examination revealed a neoplasm composed mainly of 

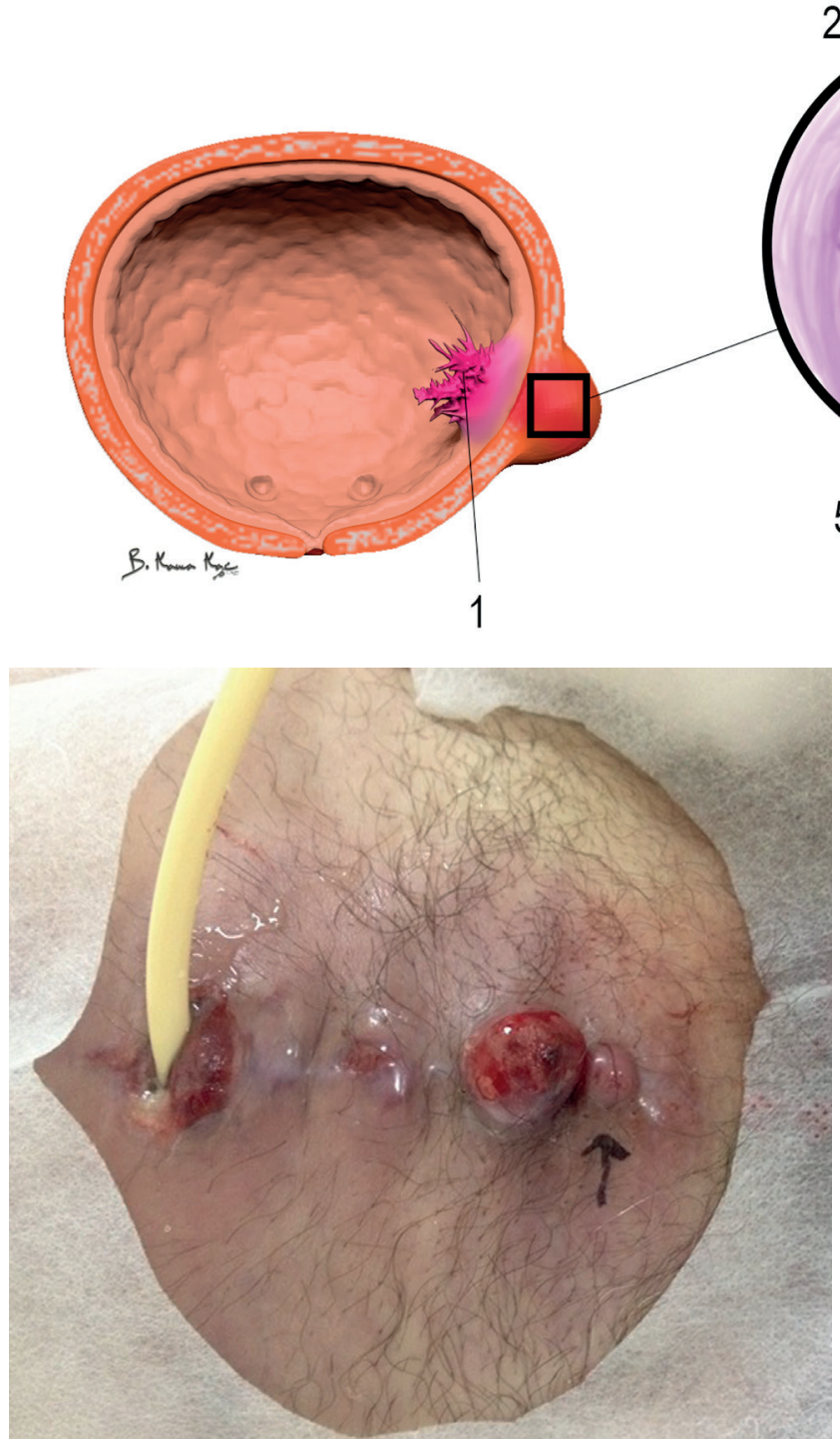

FIGURE 2: Erythematous purpuric plaque, infiltrated, located in the infraumbilical midline scar and two erythematous-wine colored nodules in the midline, suprapubic region; the black arrow marks the biopsied nodule. Suprapubic cystostomy with urine leakage

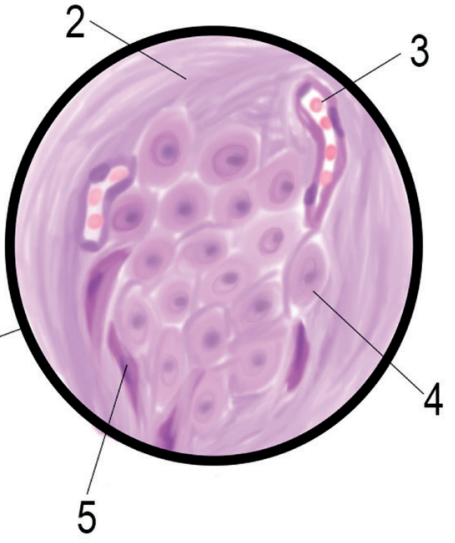

Photo: Prof. Bernard Kawa Kac.
Figure 1:

Primary neoplasm invading bladder mucosa and muscles; uncontrolled infiltrative growth with atypical epithelial cells. 2. Dissected collagen bundles; 3. Angiogenesis induced by neoplasm; 4 . Undifferentiated atypical epithelioid cells forming cords and irregular aggregates, without a definite architectural pattern.

atypical epithelioid and pleomorphic cells, disposed in large compact aggregates, without any characteristic architecture. Presence of numerous mitoses and areas of necrosis. The neoplasm occupied the entire dermis (Figure 4). A revision of the histopathology of the bladder lesion demonstrated a neoplasm predominantly composed of atypical epithelioid and pleomorphic cells, disposed in large compact aggregates, without any characteristic architecture. Presence of numerous mitoses and areas of necrosis. A neoplasm reached the muscular layer (Figure 5).

An immunohistochemical examination of the bladder lesion demonstrated neoplastic cells with the following immunomarking profile: immunopositivity with the antivimentin (diffuse) and cytokeratin antibodies AE1/AE3 (rare cells); immunonegativity with the anti CD34 antibody (Figure 6).

An immunohistochemical examination of the cutaneous nodule showed neoplastic cells with the following immunomarking profile: immunopositivity with the antivimentin antibody (diffuse); imunonegativity with all other tested antibodies: cyto-
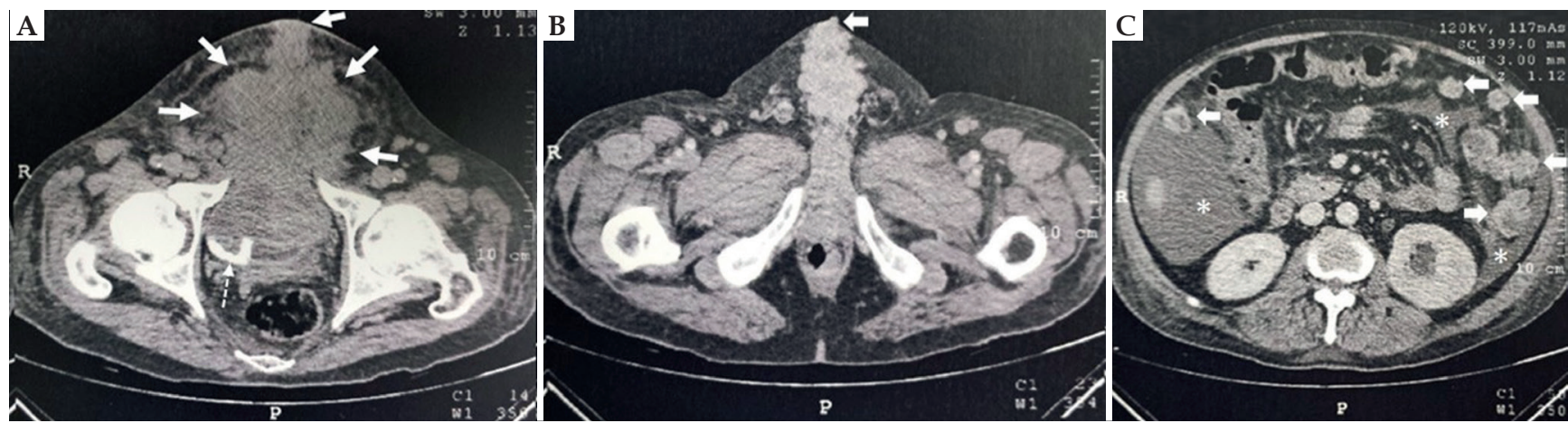

FIGURE 3: Tomography of abdomen and pelvis: (a) Cut at bladder level, thickening of right vesical wall associated with densification of adjacent fat and mass of heterogeneous enhancement infiltrating the abdominal wall up to the epidermis (white arrows). Contrast excreted by the kidneys in the interior of the bladder (dotted arrow); (b) Cut below the pubic symphysis, showing extension of the same mass through the subcutaneous tissue and the biopsied nodule (white arrow); (c) Cut at kidney level showing free liquid $\left(^{*}\right)$ and peritoneal nodules, of irregular outline and heterogeneous enhancement, suggestive of secondary implants (white arrows). 

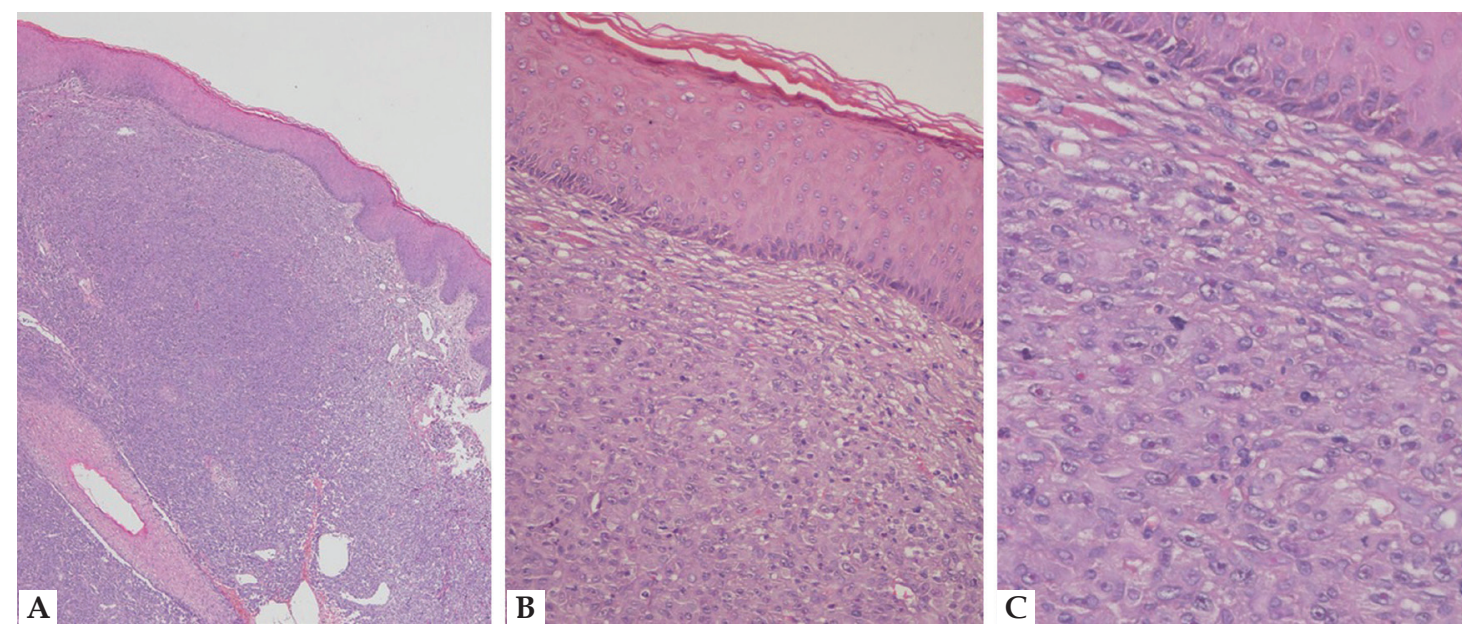

Figure 4: Skin His topathologic findings: neoplasm composed predominantly of atypical and pleomorphic epithelioid cells, disposed in large compact aggregates, without any characteristic architecture. Presence of numerous mitoses and areas of necrosis. The neoplasm occupies all the dermis (hematoxilin and eosin staining; (A) 4x; (B) 10x; (C) 40x)
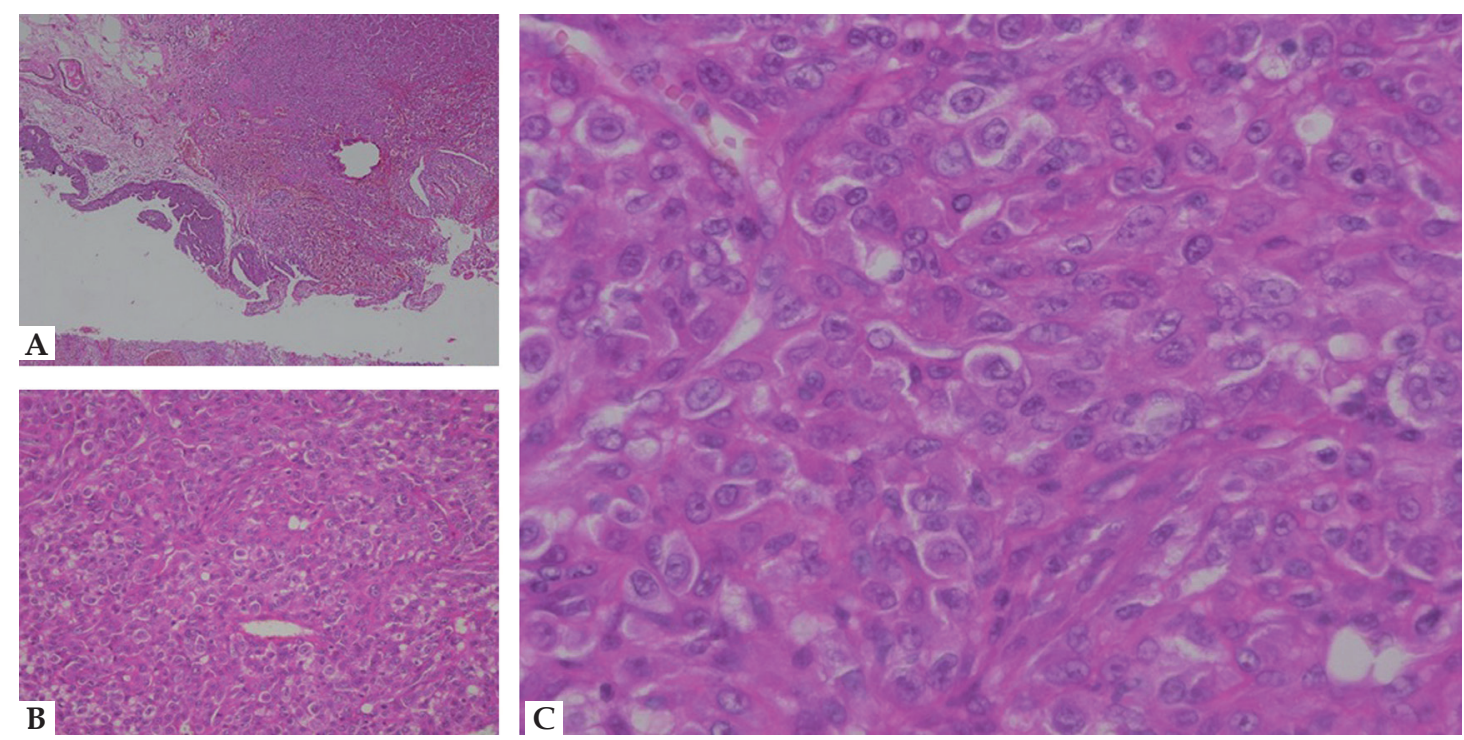

Figure 5: Bladder - Histopathologic findings: neoplasm composed predominantly of atypical and pleomorphic epithelioid cells, disposed in large compact aggregates, without any characteristic architecture. Presence of numerous mitoses and areas of necrosis. The neoplasm reaches the muscular wall [hematoxilin and eosin staining; (A) 4x; B

(B) 10x; (C) 40x)]

keratin-cocktail, clone AE1/AE3, CK5, CK7, CK20, melan-A, Renal Cell Carcinoma Marker (RCC); CD34, CD45 (LCA), protein p63, prostatic specific antigen (PSA), smooth muscle actin, protein S-100 and epithelial membrane antigen (EMA) (Figure 7).

The patient was referred to oncology for treatment, but passed away thirty days after the diagnosis of cutaneous invasion.

\section{DISCUSSION}

It is undeniable that cancer is a public health problem, whose prevention and early diagnosis should be prioritized. The diagnosis of a tumor in advanced stage implies in systemic treatment, that is, use of chemotherapy, hormone therapy or target-therapies. In these cases, local treatments, such as radiotherapy or surgery, will usually have no curative effect. ${ }^{1,4}$ The invasive urothelial carcinoma is recognized for its capacity of divergent differentiation and presentation of morphological variants. WHO acknowledges as main variants of the urothelial carcinoma: squamous, glandular differentiation, nests, microcystic, micropapilliferous, lymphoepithelioma-simile, lymphoma-simile and plasmocytoid, sarcomatoid (with and without heterologous elements), trophoblastic differentiation, clear cells and lipidic cells. ${ }^{18,19}$

The recognition of morphological variants is of great importance in the differential diagnosis with non neoplastic lesions and other malignant neoplasms, including secondary vesical involvement by another carcinoma or sarcoma. The presence of a morphological variant is associated with a more aggressive biological behavior of urothelial carcinomas and may even reflect in the option for therapeutic conducts different from the customarily used in the conventional urothelial carcinoma. ${ }^{4,19,20}$

The sarcomatoid bladder carcinoma is a rare neoplasm composed of two different components. One is formed by epithelial tissue with malignant characteristics (carcinoma) and another has sarco- 

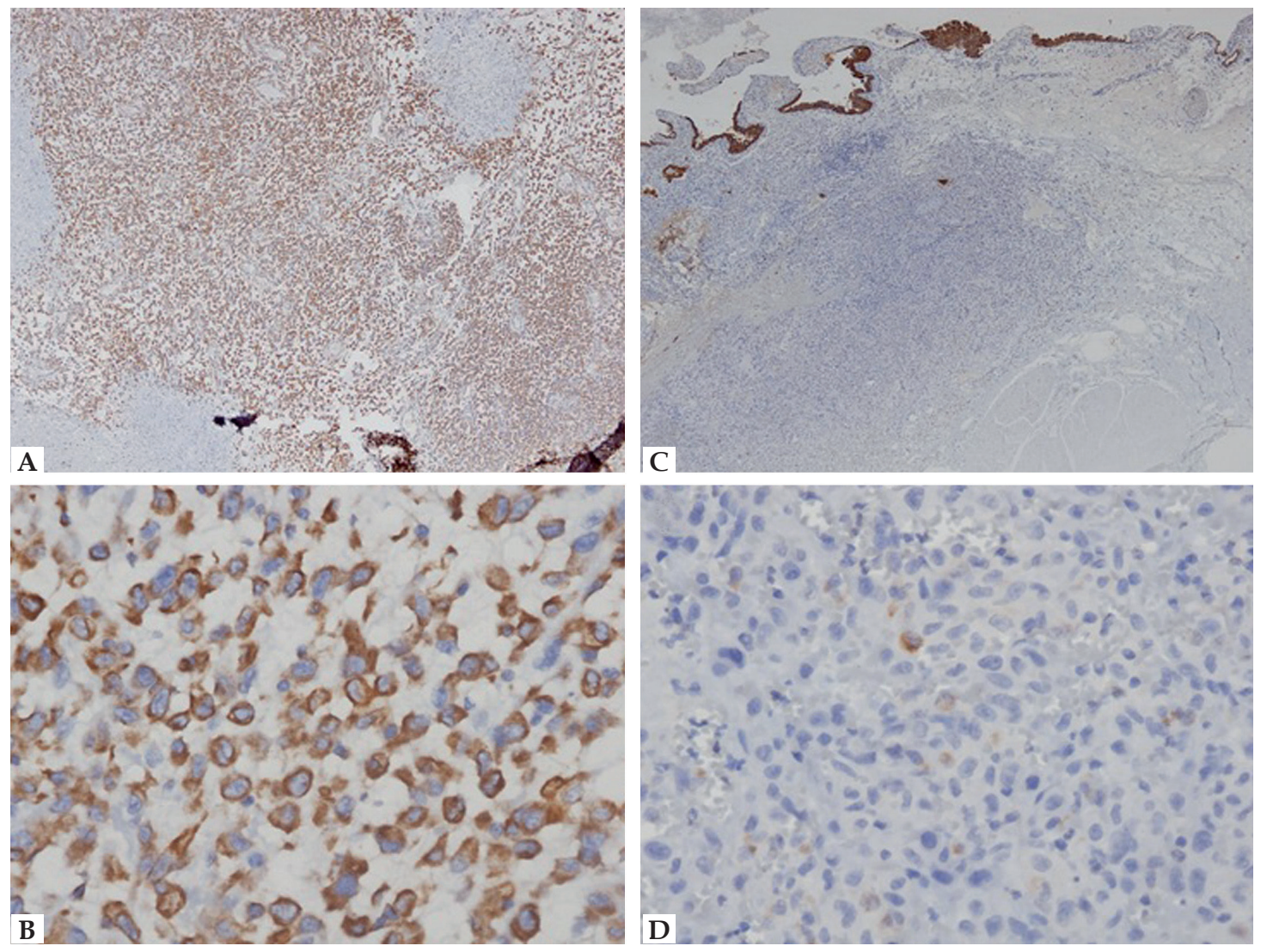

FIGURE 6: Bladder - immunomarking profile: immunopositivity with anti vimentin (diffuse) (A, $4 \mathrm{x} ; \mathrm{B}, 40 \mathrm{x})$ and cytokeratin AE1/AE3 (rare cells) $(\mathrm{C}, 4 \mathrm{x} ; \mathrm{D}$, 40x) antibodies
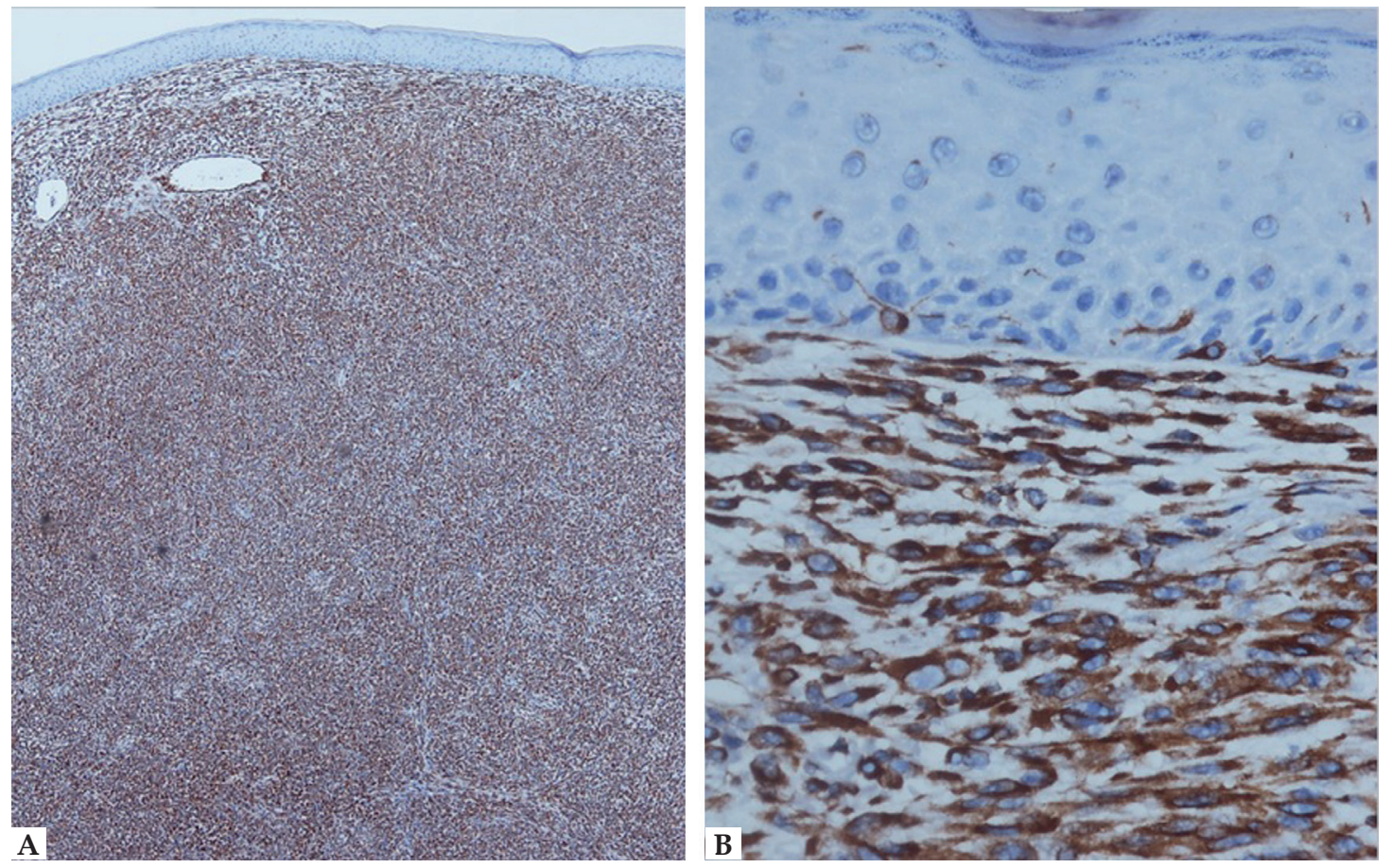

Figure 7: : Skin immunomarking profile: immunopositivity with anti vimentin (diffuse) (A, $4 x ; B, 40 x)$

matoid characteristics, of mesenchymal origin. Some authors suggest the use of the term sarcomatoid carcinoma for cases without heterologous mesenchymal elements in the composition of fusiform cells. Macroscopically, they present as exophytic polypoid masses, voluminous ( $5.7 \mathrm{~cm}$ on average) and with necrosis and ulceration areas. ${ }^{20}$

Histogenesis is controversial. Some authors suggest that these tumors develop as a result of the ability of undifferentiated, totipotentiary neoplastic 
cells to be the origin of multiple pathways of terminal differentiation in histologically recognized mesenchymal and epithelial elements. As basis for this theory stand out the existence of immunoreactivity for epithelial markers (cytokeratin and epithelial membrane antigen - EMA) in mesenchymal areas, as well as the presence of ultrastructural epithelial differentiation parameters (desmosomes and tonofilaments) in sarcomatoid elements. Other authors defend the theory that there is a tumoral "collision", saying that there are two independent malignant tumors, mutually invasive. A third theory points to the possibility of occurrence of metaplasia of malignant epithelial elements to sarcomatoid elements, based on the presence of staining for keratins (AE1/AE3) both in the epithelial component and in the mesenchymal component. ${ }^{19,20}$

The most frequently found epithelial component is the high grade transitional carcinoma $(80 \%)$, followed by squamous cell carcinoma (32\%), adenocarcinoma (26\%) and small cell carcinoma (5\%). In about $33 \%$ of cases, two or more epithelial components may coexist. As for the mesenchymal components, the most frequent is the osteosarcoma (37\%), followed by the condrosarcoma $(20-47 \%)$, the rabdomyosarcoma $(20 \%)$, the undifferentiated sarcoma of fusiform cells $(17 \%)$ and leiomyosarcoma $(7 \%) .^{20}$

As the transitional cell carcinomas, the sarcomatoid bladder carcinomas may present with hematuria, dysuria and urinary infection. The histological diagnosis is done based on the hematoxilin-eosin test and immunohistochemical study (cytokeratins in the epithelial component and vimentin, desmin HHF-35, SMA or S100 in the mesenchymal component). ${ }^{2,3,20}$
The differential diagnosis should be done with primary sarcomas, primary carcinomas with stromal metaplasia, carcinomas with pseudosarcomatous stroma, sarcomas associated with pseudoepitheliomatous hyperplasia, teratomas and prostate carcinomas with extension to the bladder. As a consequence of the rarity of bladder sarcomas in adults, the hypothesis of sarcomatoid carcinoma should be considered in the presence of a malignant tumor of fusiform cells until there is immunohistochemical confirmation. ${ }^{19,20}$

\section{CONCLUSION}

The cutaneous dissemination of urothelial neoplasms, as in other cases of disease in distant sites, is indicative of poor prognosis. It occurs mostly in late phases of the tumor and are the first sign of dissemination only in punctual cases. Its identification may be made difficult due to its presentation identical to primary skin diseases, but should be part of the differential diagnosis in oncologic patients.

In this case, as a result of the extension of the tumor and presence of metastatic nodules in the scar of the surgical wound, the propagation of the carcinoma will probably have a mixed mechanism: contiguity and iatrogenic implantation in the surgical wound. The sarcomatoid bladder carcinomas, although rare and of difficult diagnosis, deserve special attention in consequence of their aggressive behavior.] 


\section{REFERENCES}

1. Lucon AM, Falci Junior R. Câncer de bexiga. In: Lopes AC, editor. Tratado de Clínica Médica. vol. II. São Paulo: Roca; 2006. p. 2923-30.

2. Babjuk M, Burger M, Zigeuner R, Shariat SF, van Rhijn BW, Compérat E, et al. EAU guidelines on non-muscle-invasive urothelial carcinoma of the bladder: update 2013. Eur Urol. 2013;64:639-53.

3. Ploeg M, Aben KK, Kiemeney LA. The present and future burden of urinary bladder cancer in the world. World J Urol. 2009;27:289-93.

4. Inca.gov.br [Internet]. Instituto Nacional de Câncer José Alencar Gomes da Silva. Coordenação de Prevenção e Vigilância. Estimativa 2014: Incidência de Câncer no Brasil. Rio de Janeiro: INCA, 2014. 124p. [acesso 27 maio 2014]. Disponível em: http://www.inca.gov.br/estimativa/2014/estimativa-24042014.pdf

5. Freedman ND, Silverman DT, Hollenbeck AR, Schatzkin A, Abnet CC. Association between smoking and risk of bladder cancer among men and women. JAMA. 2011;306:737-45

6. Witjes JA, Compérat E, Cowan NC, De Santis M, Gakis G, Lebret T, et al. EAU guidelines on muscle-invasive and metastatic bladder cancer: summary of the 2013 guidelines. Eur Urol. 2014;65:778-92.

7. Williams PL, Warwick R, Dyson M, Bannister LH. Gray Anatomia. 37th ed. London: Guanabara Koogan; 1995.

8. Engel P, Anagnostaki L, Braendstrup 0. The muscularis mucosae of the human urinary bladder. Implications for tumor staging on biopsies. Scand J Urol Nephrol. 1992;26:249-52.

9. Amin MB. Histological variants of urothelial carcinoma: diagnostic, therapeutic and prognostic implications. Mod Pathol. 2009;22:S96-S118.

10. Alcaraz I, Cerroni L, Rütten A, Kutzner H, Requena L. Cutaneous metastases from internal malignancies: a clinicopathologic and immunohistochemical review. Am J Dermatopathol. 2012;34:347-93.

11. Hussein MR. Skin metastasis: a pathologist's perspective. J Cutan Pathol. 2010;37:e1-20.

12. Wong CY, Helm MA, Kalb RE, Helm TN, Zeitouni NC. The Presentation, Pathology, and Current Management Strategies of Cutaneous Metastasis. N Am J Med Sci. 2013;5:499-504

13. Mueller TJ, Wu H, Greenberg RE, Hudes G, Topham N, Lessin SR, et al. Cutaneous metastases from genitourinary malignancies. Urology. 2004;63:1021-6.

14. Block CA, Dahmoush L, Konety BR. Cutaneous metastases from transitional cell carcinoma of the bladder. Urology. 2006;67:846.e15-7.

15. Akman Y, Cam K, Kavak A, Alper M. Extensive cutaneous metastasis of transitional cell carcinoma of the bladder. Int J Urol. 2003;10:103-4.

16. Swick BL, Gordon JR. Superficially invasive transitional cell carcinoma of the bladder associated with distant cutaneous metastases. J Cutan Pathol. 2010;37:1245-50.

17. Jiang J, Ulbright TM, Younger C, Sanchez K, Bostwick DG, Koch MO, et al. Cytokeratin 7 and cytokeratin 20 in primary urinary bladder carcinoma and matched lymph node metastasis. Arch Pathol Lab Med. 2001;125:921-3.

18. Mattedi RL. Carcinomas uroteliais de bexiga: aspectos anatomopatológicos e imuno-histoquímicos. Pesquisa de metaloproteinases de matriz utilizando a técnica de tissue microarray (TMA) [tese]. São Paulo (SP): Universidade de São Paulo; 2011. 184 p.

19. Venyo AK, Titi S. Sarcomatoid variant of urothelial carcinoma (carcinosarcoma, spindle cell carcinoma): a review of the literature. ISRN Urol. 2014;2014:794563.

20. Silva CB, Alves MC, Ribeiro JC, Garcia P, Santos AR. Carcinoma Sarcomatóide da Bexiga. Acta Urológica. 2006;23:61-4.

\author{
MAILING ADDRESS: \\ Fred Bernardes Filho \\ Rua Marquês de Caxias, 9, Sobrado \\ Centro. \\ 24030-050. -Niterói - RJ \\ Brazil \\ E-mail:f9filho@gmail.com
}

How to cite this article: Bernardes Filho F, Neves DG, Melo ASA, Cruz MF, Pires ARC, Kac BK, Lupi O. Cutaneous invasion from sarcomatoid urothelial carcinoma: clinical and dermatopathologic features. An Bras Dermatol. 2016;91(1):73-9. 